\title{
The future of lung cancer screening with low-dose computed tomography
}

Michael T. Jaklitsch, MD, FACS, ${ }^{\mathrm{a}}$ and Francine L. Jacobson, MD, MPH ${ }^{\mathrm{b}}$

Feature Editor Note-Responsible for the greatest number of cancer-related deaths in the United States, lung cancer is a formidable diagnosis. Only 19\% of those diagnosed with lung cancer will be alive 5 years later and this is largely because the great majority of patients will have metastatic disease at the time of their presentation. Whereas less than one fifth of patients will be diagnosed with a stage I cancer, their disease is frequently curable. Thus, earlier diagnosis has obvious potential to improve survival. Effective platforms for cancer screening identify cancers at earlier stages, reduce the chance that the screened will die from their cancer, and have more potential benefit than harm. In the not-too-distant past, the results of the National Lung Screening Trial (NSLT) were published (2011) and demonstrated that screening highrisk patients with low-dose computed tomography reduced mortality from lung cancer by $20 \%$. In the present, lung cancer screening is commonly practiced alongside timehonored screening examinations for breast, colon, and cervical cancers. As should be expected, the widespread adoption of lung cancer screening has provided insight to improve its effectiveness. In this Invited Expert Opinion article, the authors review the results of 2 recent randomized lung cancer screening trials (the Multicentric Italian Lung Detection [MILD] and NELSON studies), review longer-term results of the NSLT, and discuss highimpact elements of the future of lung cancer screening that will limit false positives and optimize risk-assessment criteria. It is safe to say that all thoracic surgeons will find themselves in conversation with their patients about lung cancer screening and they will be well served by the proceeding that follows.

Bryan M. Burt, MD, FACS

From the ${ }^{\mathrm{a}}$ Division of Thoracic Surgery, Department of Surgery, and ${ }^{\mathrm{b}}$ Division of Thoracic Radiology, Department of Radiology, Brigham and Women's Hospital, Boston, Mass.

Received for publication Aug 30, 2019; revisions received Oct 28, 2019; accepted for publication Nov 3, 2019; available ahead of print Feb 19, 2020.

Address for reprints: Michael T. Jaklitsch, MD, FACS, Division of Thoracic Surgery, Brigham and Women's Hospital, 75 Francis St, Boston, MA 02115 (E-mail: mjaklitsch@bwh.harvard.edu).

J Thorac Cardiovasc Surg 2020;160:289-94 $0022-5223 / \$ 36.00$

Copyright (c) 2020 Published by Elsevier Inc. on behalf of The American Association for Thoracic Surgery

https://doi.org/10.1016/j.jtcvs.2019.11.141

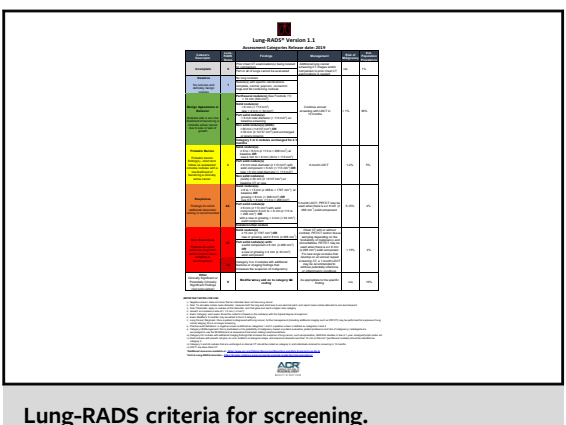

Lung-RADS criteria for screening.

CENTRAL MESSAGE

Since the adoption of lung cancer screening by the USPSTF and before their next scheduled review, there has been new evidence to inform clinicians about the future of lung cancer screening and potential changes.

This Invited Expert Opinion provides a perspective on the following paper: Nature Medicine. 2019;25:954-961. https://doi.org/10.1038/s41591-019$0447-\mathrm{x}$

The US Preventive Services Task Force (USPSTF) provided a "B" grade in December 2013 for annual lung cancer screening with low-dose computed tomography (LDCT) in smokers and former smokers aged 55 to 80 years with 30 pack years tobacco. " $\mathrm{B}$ " grade means the service is recommended and that there is evidence from a randomized control trial that there is moderate certainty of substantial benefit. In the case of LDCT to screen for lung cancer, the USPSTF gave a "B" rating due to a single randomized control trial known as the National Lung Screening Trial (NLST, covered later in this report). ${ }^{2}$ The USPSTF recommendation is coming up for review, and it is appropriate to contemplate the future of lung cancer screening.

Before LDCT screening, $56 \%$ of patients with lung cancer presented as metastatic stage IV and only $17 \%$ of all 
lung cancer victims survived 5 years. ${ }^{3}$ Screening is designed to detect cancers at an early stage and before a workup for an overt symptom of cancer.

The current use of LDCT to screen for lung cancer is based primarily on 1 major program and the ensuing clinical trial that followed. The International Early Lung Cancer Action Program established the value of LDCT in 2006 in a non-randomized application of LDCT for 36,567 screened smokers, with $85 \%$ of the detected lung cancers being stage 1 (stage shift). ${ }^{4}$ This provided the scientific background of the huge randomized National Cancer Institute-sponsored NLST. $^{2}$

Published in 2011, the NLST was a game changer, with $90 \%$ power to find a $20 \%$ difference in lung cancerspecific mortality among 53,452 participants. This randomized study was terminated early due to achieving the $20 \%$ lung cancer-specific mortality reduction after 6 years of follow-up. The next step was to convert data from a prospective randomized clinical trial to public policy (ie, actually screen for lung cancer).

The National Coverage Decision by Centers for Medicaid Services (CMS) on Feb 5, 2015, ended several decades of debates and established a public policy of providing coverage for LDCT to screen for lung cancer in smokers and former smokers aged 55 to 77 years with a 30-pack year smoking history and quit time in former smokers of 15 or fewer years. CMS-mandated screening must include shared-decision making with discussion of the risks and benefits of screening as well as tobacco cessation counseling. ${ }^{5}$

Many critics still question the evidence for screening, considering that the NLST was the only trial published at the time of the of the CMS decision that showed a lung cancer-specific mortality reduction. There have been other smaller, underpowered randomized trials testing LDCT as a lung cancer screen. DANTE (2476 patients), ${ }^{6}$ Danish Lung Cancer Screening Trial (4104 participants), ${ }^{7}$ and ITALUNG (3206 participants) ${ }^{8}$ failed to show a lung cancer-specific mortality reduction. The NLST had 53,454 participants, nearly 4 times more than all the other trials combined.

There is new evidence to further support the role of LDCT screening. In the last year, additional long-term analysis of NLST data and 2 European trials add this support.

The results of the Multicentric Italian Lung Detection (MILD) study were published in April 2019. ${ }^{9}$ This study randomized 4099 participants aged 49 to 75 years with at least 20 pack-year history of smoking, currently smoking within the past 10 years, to LDCT or no intervention. Statistical power was achieved by continuing the screening for up to 10 years. MILD found a significant $39 \%$ reduction in the relative risk of lung cancer mortality and $20 \%$ risk reduction in all-cause mortality at 10 years. These are larger than the effects seen in NLST at 6 years. Variables such as frequency of scans, ages of patients, identification of high-risk cohorts, and the length of the program can be expected to directly influence the future of LDCT screening of lung cancer.

Long-term follow-up analysis of the NLST was published in July of 2019. ${ }^{10}$ It is important to understand the design of the NLST to judge interpretations of the trial. Randomization in the NLST was to either LDCT or chest radiograph for a total of 3 screens only, 1 year apart (designated time $\mathrm{T} 0, \mathrm{~T} 1$, and $\mathrm{T} 2$ ). Thus, active screening would occur in the first 3 years, and then the participants were followed for up to 12 years afterward. As a result, detected early-stage lung cancers would be expected to be found in the first 5 years. By the seventh year, there should not be much difference in the rate of new lung cancers in the 2 arms, since the screening intervention had stopped. This proved to be true. The original publication of the NLST results in November 2011 demonstrated a significant lung cancer-specific mortality reduction of $20 \%$, detected at 6.5 years of follow-up. When the follow-up was extended beyond 11 years, there was no difference in the number of lung cancers that appeared within each arm (relative risk, 1.01 ), but there was still an $8 \%$ reduction in lung cancerspecific mortality (relative risk, 92\%) in the LDCT arm. That means that there was no difference in the total number of cancers that appeared in each arm over 12 years. However, screening in the first 3 years in the LDCT arm detected and cured early-stage lung cancers and reduced the lung cancer-specific mortality. The difference in lung cancer mortality between LDCT and chest radiographs was $20 \%$ at 6 years and still $8 \%$ at 9 years after the last screening computed tomography (CT). Furthermore, long-term analysis of the NLST showed successful stage shifting with a decrease in stage IV and an increase in stage 1 detected by LDCT. Stage IV was detected $27.5 \%$ in the LDCT arm compared with $35.5 \%$ in the chest radiograph arm. Stage 1 was detected in $39.6 \%$ of the LDCT arm and $27.5 \%$ of the chest radiograph arm.

The third source of new data for LDCT screening is the NELSON trial from the Netherlands. ${ }^{11}$ NELSON is the next largest screening trial after NLST, randomizing 15,792 individuals between the ages of 50 and 75 years to receive LDCT at baseline and 1, 3, and 5.5 years or no screening. Results have only been published in abstract form at the 19th World Conference on Lung Cancer in 2018, but LDCT screening reduced lung cancer deaths by $26 \%$ in men and $39 \%$ in women compared with the control group over a 10-year period. The long-term analysis of the NLST trial also showed increased benefit for women, but this did not achieve statistical significance.

These 3 new pieces of evidence further support the "B" grade by the USPSTF and silences previous criticism that a single trial, even as well designed as the NLST, could not convincingly prove the value of LDCT screening. Now, further long-term evidence of the NLST and the new 
information from the MILD and Nelson trials substantiate the " $\mathrm{B}$ " grade and may lead to a USPSTF "A" grade, which is reserved for "high certainty that the net benefit is substantial." 1

Before the acceptance of LDCT screening, there was controversy concerning the possibility of overdiagnosis: the identification of lung cancers that were unlikely to cause death of the patient due to competing causes. The fear of overdiagnosis of lung cancer proved to be unfounded in the long-term analysis of the NLST. The overdiagnosis rate was $3 \%$, with the majority of these due to detection of bronchoalveolar carcinoma (or minimally invasive adenocarcinoma or adenocarcinoma in-situ).$^{10}$ The second issue regards nodules that are very small and unlikely to represent disease. In the NLST, any noncalcified nodule measuring $4 \mathrm{~mm}$ or greater was classified as "positive, suspicious for lung cancer." As a result, 39.1\% of the LDCT group had at least 1 positive read during the screening portion of the trial. ${ }^{2}$ The diagnostic evaluation most often used to evaluate a small nodule was a repeat scan in 3 to 6 months. This low diameter threshold of $4 \mathrm{~mm}$ likely cast too wide a net. The overwhelming majority of nodules between 4 and $6 \mathrm{~mm}$ are benign ${ }^{12,13}$ or, if malignant, unlikely to upstage before the next annual scan. ${ }^{14}$ Finally, in analysis of the International Early Lung Cancer Action Program, it was shown that increasing the size threshold from 4 to $6 \mathrm{~mm}$ in diameter resulted in fewer false positives without changing the rate of cancer diagnosis. ${ }^{15}$

The detection of clinically insignificant lung nodules can be dramatically reduced by the institution of a standardized nodule management system, similar to that used in mammography. The American College of Radiology has developed the Lung-RADS classification system (Figure 1). ${ }^{16}$ Lung-RADS is a quality assurance tool designed to standardize lung cancer screening CT reporting and management recommendations, reduce confusion in lung cancer screening $\mathrm{CT}$ interpretations, and facilitate outcome monitoring. If there is no nodule, the scan is categorized as Lung-RADS 1. A nodule less than $6 \mathrm{~mm}$ as defined by mean diameter is Lung-RADS 2 . The probability that a nodule less than $6 \mathrm{~mm}$ is a malignancy is $<1 \%$. These 2 groups are considered a negative scan and there is no recommended workup other than the next annual scan. About $90 \%$ of all scans are expected to fall within this group. A new nodule of at least $6 \mathrm{~mm}$ is considered Lung-RADS 3 with a malignant probability of $2 \%$ and is reimaged in 6 months with a repeat LDCT. Lung-RADS 4 are suspicious nodules and suggestions for further workup may include a short interval LDCT of 3 months or a more invasive workup.

A study of Lung-RADS criteria applied to the 26,722 LDCT participants in the NLST increased the specificity of LDCT from $73.4 \%$ to $87.2 \%$ and reduced the falsepositive rate from $26.6 \%$ to $12.8 \% .{ }^{17}$ An estimated 117 invasive procedures ( $23.4 \%$ of all the invasive procedures) in the NLST would have been prevented if Lung-RADS uniform reporting system had been used. Furthermore, LungRADS reduced the rate for mediastinoscopy, videoassisted thoracoscopic surgery, or thoracotomy of $0.3 \%$ for false positives among all those screened. ${ }^{18}$

For Medicare coverage of LDCT screening, centers must have a standardized registry and a standardized method of judging positive scans. We predict that Lung-RADS will be accepted as the standard judging method for nearly all screening centers, although evidence exists that volumetric analysis such as that used in the NELSON trial has a lower false-positive rate and greater efficacy. ${ }^{11}$ While no one expects another trial of the scale of the NLST, the CMS-required clinical registry for screening programs has offered a pathway of data collection to improve future guidelines based on patient outcomes. The data will help to better decide additional risk factors for lung cancer to eventually look beyond cigarettes in defining lung cancer risk.

Mathematical models are available online for each individual to calculate their personal risk of lung cancer. The American Association for Thoracic Surgery calculator can be accessed at: https://www.aats.org/AATSIMIS/iParts/ Custom/Controls/LungCancerScreening/lungcancer.html. ${ }^{19}$

In our opinion, modeling of risk has been underemployed. We now have externally validated risk modules including the Kovalchik model, ${ }^{20}$ the Katki model, ${ }^{21}$ and the $\mathrm{PLCO}_{\mathrm{m} 2012}$ model as well as its secondary analysis of the NLST data. ${ }^{22-}$

24 Both the National Comprehensive Cancer Network and American Association for Thoracic Surgery have recommended screening for patients with only 20 pack years smoking exposure and at least 1 other variable that increases their risk of malignancy. ${ }^{25,26}$ There is not a risk threshold that is agreed on to recommend lung cancer screening, but the American College of Radiology recommended increased frequency of LDCT at 6 months for those patients felt to be at $2 \%$ risk of lung cancer. ${ }^{16}$ Twenty percent of the lung cancers in women occur in never smokers. How can we extend screening benefits to this population? Mathematical modeling may have the solution. ${ }^{22,27,28}$ The models show the risk for lung cancer in the absence of tobacco smoke exposure can be greater in individuals with multiple small risk factors, including family history of early-onset lung cancer and personal history of previous pneumonia. In our analysis of non-tobacco causes of lung cancer, especially nonsmoking female patients, we found a family history of a first-degree relative developing lung cancer before age 60 years combines with age to produce a risk of lung cancer that exceeds $5 \%$ over the next 10 years. ${ }^{29}$ Similar models have examined light smokers or more distant quit rates such as the HUNT lung prediction model. ${ }^{30}$

If the selection of the screened population was chosen by baseline risk of developing lung cancer for each individual, instead of clinical thresholds (such as 30 pack 


\begin{tabular}{|c|c|c|c|c|c|}
\hline \multicolumn{6}{|c|}{$\begin{array}{c}\text { Lung-RADS }{ }^{\circledR} \text { Version } 1.1 \\
\text { Assessment Categories Release date: } 2019\end{array}$} \\
\hline $\begin{array}{l}\text { Category } \\
\text { Descriptor }\end{array}$ & $\begin{array}{l}\text { Lung- } \\
\text { RADS } \\
\text { Score }\end{array}$ & Findings & Management & $\begin{array}{c}\text { Risk of } \\
\text { Malignancy }\end{array}$ & \begin{tabular}{|c|} 
Est. \\
Population \\
Prevalence
\end{tabular} \\
\hline Incomplete & 0 & $\begin{array}{l}\text { Prior chest CT examination(s) being located } \\
\text { for comparison } \\
\text { Part or all of lungs cannot be evaluated }\end{array}$ & $\begin{array}{l}\text { Additional lung cancer } \\
\text { screening CT images and/or } \\
\text { comparison to prior chest CT } \\
\text { examinations is needed }\end{array}$ & $n / a$ & $1 \%$ \\
\hline $\begin{array}{c}\text { Negative } \\
\text { No nodules and } \\
\text { definitely benign } \\
\text { nodules }\end{array}$ & 1 & $\begin{array}{l}\text { No lung nodules } \\
\text { Nodule(s) with specific calcifications: } \\
\text { complete, central, popporn, concentric } \\
\text { rings and fat containing nodules }\end{array}$ & \multirow{6}{*}{$\begin{array}{l}\text { Continue annual } \\
\text { screening with LDCT in } \\
12 \text { months }\end{array}$} & \multirow{6}{*}{$<1 \%$} & \multirow{6}{*}{$90 \%$} \\
\hline \multirow{5}{*}{$\begin{array}{l}\text { Benign Appearance or } \\
\text { Behavior } \\
\text { Nodules with a very low } \\
\text { lokelihood of becoming a a } \\
\text { clinically active cancer } \\
\text { due to size or lack of } \\
\text { growth }\end{array}$} & \multirow{5}{*}{2} & $\begin{array}{l}\text { Perifissural nodule(s) (See Footnote 11) } \\
<10 \mathrm{~mm}\left(524 \mathrm{~mm}^{3}\right)\end{array}$ & & & \\
\hline & & $\begin{array}{l}\text { Solid nodule(s): } \\
\quad<6 \mathrm{~mm}\left(<113 \mathrm{~mm}^{3}\right) \\
\text { new }<4 \mathrm{~mm}\left(<34 \mathrm{~mm}^{3}\right)\end{array}$ & & & \\
\hline & & $\begin{array}{l}\text { Part solid nodule(s): } \\
<6 \mathrm{~mm} \text { total diameter }\left(<113 \mathrm{~mm}^{3}\right) \text { on } \\
\text { baseline screening }\end{array}$ & & & \\
\hline & & $\begin{array}{l}\text { Non solid nodule(s) }(\mathbf{G G N}): \\
<30 \mathrm{~mm}\left(<14137 \mathrm{~mm}^{3}\right) \text { OR } \\
\geq 30 \mathrm{~mm}\left(\geq 14137 \mathrm{~mm}^{3}\right) \text { and unchanged } \\
\text { or slowly growing }\end{array}$ & & & \\
\hline & & $\begin{array}{l}\text { Category } 3 \text { or } 4 \text { nodules unchanged for } \geq 3 \\
\text { months }\end{array}$ & & & \\
\hline \multirow{3}{*}{$\begin{array}{l}\text { Probably Benign } \\
\text { Probably benign } \\
\text { finding(s) - - short term } \\
\text { follow up suggested; } \\
\text { includes nodules with a } \\
\text { low likelihood of } \\
\text { becoming a clinically } \\
\text { active cancer }\end{array}$} & \multirow{3}{*}{3} & $\begin{array}{l}\text { Solid nodule(s): } \\
\geq 6 \text { to }<8 \mathrm{~mm}\left(\geq 113 \text { to }<268 \mathrm{~mm}^{3}\right) \text { at } \\
\text { baseline } \mathrm{OR} \quad<\mathrm{mm}\left(34 \text { to }<113 \mathrm{~mm}^{3}\right) \\
\text { new } 4 \mathrm{~mm} \text { to }<6 \mathrm{~m}\end{array}$ & \multirow{3}{*}{6 month LDCT } & \multirow{3}{*}{$1-2 \%$} & \multirow{3}{*}{$5 \%$} \\
\hline & & \begin{tabular}{|l|} 
Part solid nodule(s) \\
$\geq 6 \mathrm{~mm}$ total diameter $\left(\geq 113 \mathrm{~mm}^{3}\right)$ with \\
solid component $<6 \mathrm{~mm}\left(<113 \mathrm{~mm}^{3}\right)$ OR \\
new $<6 \mathrm{~mm}$ total diameter $\left(<113 \mathrm{~mm}^{3}\right)$ \\
\end{tabular} & & & \\
\hline & & \begin{tabular}{|l|} 
Non solid nodule(s) \\
$(G G N) \geq 30 \mathrm{~mm}\left(\geq 14137 \mathrm{~mm}^{3}\right)$ on \\
baseline CT or new
\end{tabular} & & & \\
\hline \multirow{3}{*}{\begin{tabular}{c|} 
Suspicious \\
Findings for which \\
additional diagnostic \\
testing is recommended
\end{tabular}} & \multirow{3}{*}{$4 \mathrm{~A}$} & $\begin{array}{l}\text { Solid nodule(s): } \\
\geq 8 \text { to }<15 \mathrm{~mm}\left(\geq 268 \text { to }<1767 \mathrm{~mm}^{3}\right) \text { at } \\
\text { baseline OR } \\
\text { growing }<8 \mathrm{~mm}\left(<268 \mathrm{~mm}^{3}\right) \mathrm{OR} \\
\text { new } 6 \text { to }<8 \mathrm{~mm}\left(113 \text { to }<268 \mathrm{~mm}^{3}\right)\end{array}$ & \multirow{3}{*}{$\begin{array}{l}3 \text { month LDCT; PET/CT may be } \\
\text { used when there is a } \geq 8 \mathrm{~mm} \text { ( }(\geq \\
\left.268 \mathrm{~mm}^{3}\right) \text { solid component }\end{array}$} & \multirow{3}{*}{$5-15 \%$} & \multirow{3}{*}{$2 \%$} \\
\hline & & $\begin{array}{l}\text { Part solid nodule(s): } \\
\geq 6 \mathrm{~mm}\left(\geq 113 \mathrm{~mm}^{3}\right) \text { with solid } \\
\text { component } \geq 6 \mathrm{~mm} \text { to }<8 \mathrm{~mm}(\geq 113 \text { to } \\
\left.<268 \mathrm{~mm}^{3}\right) \text { OR } \\
\text { with a new or growing }<4 \mathrm{~mm}\left(<34 \mathrm{~mm}^{3}\right) \\
\text { solid component }\end{array}$ & & & \\
\hline & & Endobronchial nodule & & & \\
\hline \multirow{3}{*}{$\begin{array}{l}\text { Very Suspicious } \\
\text { Findings for which } \\
\text { additional diagnostic } \\
\text { testing and/lor tissue } \\
\text { sampling is } \\
\text { recommended }\end{array}$} & \multirow[b]{2}{*}{ 4B } & $\begin{array}{l}\text { Solid nodule(s) } \\
\geq 15 \mathrm{~mm}\left(\geq 1767 \mathrm{~mm}^{3}\right) \text { OR } \\
\text { new or growing, and } \geq 8 \mathrm{~mm}\left(\geq 268 \mathrm{~mm}^{3}\right)\end{array}$ & \multirow{3}{*}{$\begin{array}{l}\text { Chest CT with or without } \\
\text { contrast, PET/CT and/or tissue } \\
\text { sampling depending on the } \\
\text { *probability of malignancy and } \\
\text { comorbidities. PET/CT may be } \\
\text { used when there is a } \geq 8 \mathrm{~mm} \\
(\geq 268 \mathrm{~mm})^{3} \text { solid component. } \\
\text { For new large nodules that } \\
\text { develop on an annual repeat } \\
\text { screening CT, a } 1 \text { month LDCT } \\
\text { may be recommended to } \\
\text { address potentially infectious } \\
\text { or inflammatory conditions } \\
\end{array}$} & \multirow{3}{*}{$>15 \%$} & \multirow{3}{*}{$2 \%$} \\
\hline & & $\begin{array}{l}\text { Part solid nodule(s) with: } \\
\text { a solid component } \geq 8 \mathrm{~mm}\left(\geq 268 \mathrm{~mm}^{3}\right) \\
\text { OR } \\
\text { a new or growing } \geq 4 \mathrm{~mm}\left(\geq 34 \mathrm{~mm}^{3}\right) \\
\text { solid component }\end{array}$ & & & \\
\hline & $4 \mathrm{X}$ & $\begin{array}{l}\text { Category } 3 \text { or } 4 \text { nodules with additional } \\
\text { features or imaging findings that } \\
\text { increases the suspicion of malignancy }\end{array}$ & & & \\
\hline $\begin{array}{c}\text { Other } \\
\text { Clinically Significant or } \\
\text { Potentially Clinically } \\
\text { Significant Findings } \\
\text { (non lung cancer) }\end{array}$ & $\mathrm{s}$ & $\begin{array}{l}\text { Modifier - may add on to category } 0.4 \\
\text { coding }\end{array}$ & $\begin{array}{l}\text { As appropriate to the specific } \\
\text { finding }\end{array}$ & n/a & $10 \%$ \\
\hline
\end{tabular}

\footnotetext{
IMPORTANT NOTES FOR USE:

1) Negative screen: does not mean that an individual does not have lung cancer

作

3) Size Thresholds: apply to nodules at first detection,
4) Growth: an increase in size of $>1.5 \mathrm{~mm}\left(>2 \mathrm{~mm}^{3}\right)$

5) Exam Category: each exam should be coded 0.4 based on the nodule(s) with the highest degree of suspicion

Exam Modifiers: S modifier may be added to the 0.4 category

Lung Cancer Diagnosis: Once a patient is

8) Practice audit definitions: a negative screen is defined as categories 1 and 2; a positive screen is defined as categories 3 and

9) Category $4 \mathrm{~B}$ Management: this is predicated on the probability of malignancy based on patient evaluation, patient preference and risk of malignancy; radiologists are

4 Category 4 X nod

11) Solid nodules with smooth margins, an oval, lentiform or triangular shape, and maximum diameter less than $10 \mathrm{~mm}$ or $524 \mathrm{~mm}^{3}$ (perifissural nodules) should be classified as

category 2

12) Category 3 and $4 \mathrm{~A}$ nodules that are unchanged on interval CT should be coded as category 2, and individuals returned to screening in 12 months

13) LDCT: low dose chest CT

"Additional resources available at - https://www.acr.org/Clinical-Resources/Reporting-and-Data-Systems/Lung-Rads

"Link to Lung-RADS calculator - https:///brocku.ca/lung-cancer-screening-and-risk-prediction/risk-calculators/
}

\section{ADPR}

FIGURE 1. Lung-RADS classification. $C T$, Computed tomography; $G G N$, ground-glass nodule; $L D C T$, low-dose computed tomography; $P E T$, positron emission tomography. Reprinted with permission. ${ }^{16}$ 
years), we believe the positive outcomes would be expected to improve and the negative consequences would be expected to decrease. The future of lung cancer screening will likely include refinement of risk assessment of eligible patients. For instance, in further analysis of the NLST, $88 \%$ of the mortality benefit was achieved by screening the $60 \%$ of participants at greatest risk. ${ }^{20}$ The $20 \%$ at lowest risk accounted for just $1 \%$ of preventable lung-cancer deaths.

Next it is important to address adherence rates. Using the National Health Interview Survey, investigators identified an increase from $3.3 \%$ in 2010 to $3.9 \%$ in 2015 $(P=.60)$ of eligible smokers who reported LDCT screen within the past 12 months. ${ }^{31}$ This number is significantly lower than for other screened cancers. ${ }^{32}$ It has been shown that geographic, socioeconomic, as well as provider-related factors continue to impact screening rates. ${ }^{33-36}$

An inexpensive test of blood, urine, or breath has not yet emerged despite active research in this regard. Some of these alternative tests are becoming available for clinical use and one day may supplant LDCT but unlikely in the near future.

Overdiagnosis of lung cancer does not appear to be a serious concern in solid nodules, but our lack of understanding of ground-glass opacities (GGO) can lead to interventions for some lesions that would never advance to full malignant potential. ${ }^{10}$ Further data are needed to understand single-site GGO, multifocal disease, and development of part-solid nodules. The screening guidelines for these abnormalities will likely change over the next decade.

\section{CONCLUSIONS}

The future of lung cancer screening with LDCT looks strong with new data to support its use. Standardization of reporting and management will increase the benefit and decrease the harms of screening. The future use of mathematic models may further identify the screen appropriate cohorts. More work is needed in understanding the natural history of GGOs to refine the screening recommendations for this subgroup. We believe 2 underappreciated aspects of the LDCT screening benefit is the clinical registry and support of smoking cessation. One provides data for future refinement of the program, and one tries to eliminate the underlying cause.

\section{Conflict of Interest Statement}

Authors have nothing to disclose with regard to commercial support.

\section{References}

1. Final Update Summary: Lung Cancer: Screening-US Preventive Services Task Force. Available at: https://www.uspreventiveservicestaskforce.org/Page/ Document/UpdateSummaryFinal/lung-cancer-screening. Accessed August 7, 2019.
2. National Lung Screening Trial Research Team, Aberle DR, Adams AM, Berg CD, Black WC, Clapp JD, et al. Reduced lung-cancer mortality with low-dose computed tomographic screening. N Engl J Med. 2011;365:395-409.

3. Cancer of the Lung and Bronchus-Cancer Stat Facts. SEER. Available at: https://seer.cancer.gov/statfacts/html/lungb.html. Accessed August 7, 2019.

4. International Early Lung Cancer Action Program Investigators, Henschke CI, Yankelevitz DF, Libby DM, Pasmantier MW, Smith JP, et al. Survival of patients with stage I lung cancer detected on CT screening. N Engl J Med. 2006;355: 1763-71.

5. Lung Cancer Screening Coverage. Available at: https://www.medicare.gov/ coverage/lung-cancer-screenings. Accessed August 28, 2019.

6. Infante M, Lutman FR, Cavuto S, Brambilla G, Chiesa G, Passera E, et al. Lung cancer screening with spiral CT: baseline results of the randomized DANTE trial. Lung Cancer. 2008;59:355-63.

7. Wille MM, Dirksen A, Ashraf H, Saghir Z, Bach KS, Brodersen J, et al. Results of the randomized Danish lung cancer screening trial with focus on high-risk profiling. Am J Respir Crit Care Med. 2016;193:542-51.

8. Paci E, Puliti D, Lopes Pegna A, Carrozzi L, Picozzi G, Falaschi F, et al. Mortality, survival and incidence rates in the ITALUNG randomised lung cancer screening trial. Thorax. 2017;72:825-31.

9. Pastorino U, Silva M, Sestini S, Sabia F, Boeri M, Cantarutti A, et al. Prolonged lung cancer screening reduced 10-year mortality in the MILD Trial. Ann Oncol. 2019;30:1162-9.

10. National Lung Screening Trial Research Team. Lung cancer incidence and mortality with extended follow-up in the National Lung Screening Trial. J Thorac Oncol. 2019;14:1732-42.

11. de Koning HJ, van der Aalst CM, Ten Haaf K, Oudkerk M. PL02.05 Effects of volume CT lung cancer screening: mortality results of the NELSON randomised-controlled population-based trial. J Thorac Oncol. 2018;13:S185.

12. Wahidi MM, Govert JA, Goudar RK, Gould MK, McCrory DC, American College of Chest Physicians. Evidence for the treatment of patients with pulmonary nodules: when is it lung cancer? ACCP evidence-based clinical practice guidelines (2nd edition). Chest. 2007;132(3 suppl):94S-107S.

13. Horeweg N, van Rosmalen J, Heuvelmans MA, van der Aalst CM, Vliegenthart R, Scholten ET, et al. Lung cancer probability in patients with CT-detected pulmonary nodules: a prespecified analysis of data from the NELSON trial of low-dose CT screening. Lancet Oncol. 2014;15:1332-41.

14. Casiraghi M, Travaini LL, Maisonneuve P, Tessitore A, Brambilla D Agoglia BG, et al. Lymph node involvement in T1 non-small-cell lung cancer: could glucose uptake and maximal diameter be predictive criteria? Eur J Cardiothorac Surg. 2011;39:e38-43.

15. Henschke CI, Yip R, Yankelevitz DF, Smith JP, International Early Lung Cancer Action Program Investigators*. Definition of a positive test result in computed tomography screening for lung cancer: a cohort study. Ann Intern Med. 2013; 158:246-52.

16. Lung-RADS ${ }^{\mathrm{TM}}$ Version 1.0 Assessment Categories Release date: April 28, 2014 Available at: LungRADS_AssessmentCategories.pdf. https://www.acr.org/-/media/ ACR/Files/RADS/Lung-RADS/LungRADS_AssessmentCategories.pdf. Accessed August 28, 2019.

17. Pinsky PF, Gierada DS, Black W, Munden R, Nath H, Aberle D, et al. Performance of Lung-RADS in the national lung screening trial: a retrospective assessment. Ann Intern Med. 2015;162:485-91.

18. Walker BL, Williamson C, Regis SM, McKee AB, D'Agostino RS, Hesketh PJ et al. Surgical outcomes in a large, clinical, low-dose computed tomographic lung cancer screening program. Ann Thorac Surg. 2015;100:1218-23.

19. Lung Cancer Assessment Tool - AATS.org. Available at: https://www.aats.org/ AATSIMIS/iParts/Custom/Controls/LungCancerScreening/lungcancer.html. Accessed August 28, 2019

20. Kovalchik SA, Tammemagi M, Berg CD, Caporaso NE, Riley TL, Korch M, et al Targeting of low-dose CT screening according to the risk of lung-cancer death. $N$ Engl J Med. 2013;369:245-54.

21. Katki HA, Kovalchik SA, Berg CD, Cheung LC, Chaturvedi AK. Development and validation of risk models to select ever-smokers for CT lung cancer screening. JAMA. 2016;315:2300-11.

22. Tammemagi CM, Pinsky PF, Caporaso NE, Kvale PA, Hocking WG, Church TR, et al. Lung cancer risk prediction: prostate, lung, colorectal and ovarian cancer screening trial models and validation. J Natl Cancer Inst. 2011;103: 1058-68.

23. Tammemägi MC, Katki HA, Hocking WG, Church TR, Caporaso N, Kvale PA et al. Selection criteria for lung-cancer screening. N Engl J Med. 2013;368: 728-36. 
24. Tammemägi MC, Haaf K ten, Toumazis I, Kong CY, Han SS, Jeon J, et al. Development and validation of a multivariable lung cancer risk prediction model that includes low-dose computed tomography screening results: a secondary analysis of data from the national lung screening trial. JAMA Netw Open. 2019;2: e190204.

25. Wood DE, Kazerooni EA, Baum SL, Eapen GA, Ettinger DS, Hou L, et al. Lung cancer screening, version 3.2018, NCCN clinical practice guidelines in oncology. J Natl Compr Canc Netw. 2018;16:412-41.

26. Jaklitsch MT, Jacobson FL, Austin JH, Field JK, Jett JR, Keshavjee S, et al. The American Association for Thoracic Surgery guidelines for lung cancer screening using low-dose computed tomography scans for lung cancer survivors and other high-risk groups. J Thorac Cardiovasc Surg. 2012;144:33-8.

27. Ten Haaf K, Jeon J, Tammemägi MC, Han SS, Kong CY, Plevritis SK, et al. Risk prediction models for selection of lung cancer screening candidates: a retrospective validation study. PLoS Med. 2017;14:e1002277.

28. Cassidy A, Myles JP, van Tongeren M, Page RD, Liloglou T, Duffy SW, et al. The LLP risk model: an individual risk prediction model for lung cancer. Br J Cancer. 2008;98:270-6.

29. Bravo-Iñiguez CE, Fox SW, De Leon LE, Tarascio JN, Jaklitsch MT, Jacobson FL. Cumulative nonsmoking risk factors increase the probability of developing lung cancer. J Thorac Cardiovasc Surg. 2019;158:1248-54.e1.
30. Markaki M, Tsamardinos I, Langhammer A, Lagani V, Hveem K, Røe OD. A Validated clinical risk prediction model for lung cancer in smokers of all ages and exposure types: A HUNT Study. EBioMedicine. 2018;31:36-46.

31. Jemal A, Fedewa SA. Lung cancer screening with low-dose computed tomography in the United States-2010 to 2015. JAMA Oncol. 2017;3:1278-81.

32. Clarke TC, Soler-Vila H, Fleming LE, Christ SL, Lee DJ, Arheart KL. Trends in adherence to recommended cancer screening: the US population and working cancer survivors. Front Oncol. 2012;2:190.

33. Eberth JM. Geographic availability of low-dose computed tomography for lung cancer screening in the United States, 2017. Prev Chronic Dis. 2018;15.

34. Duong DK, Shariff-Marco S, Cheng I, Naemi H, Moy LM, Haile R, et al. Patient and primary care provider attitudes and adherence towards lung cancer screening at an academic medical center. Prev Med Rep. 2017;6:17-22.

35. Nhung BC, Lee YY, Yoon H, Suh M, Park B, Jun JK, et al. Intentions to undergo lung cancer screening among Korean men. Asian Pac J Cancer Prev. 2015;16: 6293-8.

36. Chalian H, Khoshpouri P, Iranmanesh AM, Mammarappallil JG, Assari S. Lung cancer screening patient-provider discussion: where do we stand and what are the associated factors? SAGE Open Med. 2019;7: 2050312119854265 . 